\title{
MEASURING PARASITOID CARBOHYDRATE LEVELS TO IMPROVE BIOLOGICAL CONTROL
}

\author{
H.D. VATTALA ${ }^{1}$, S.D. WRATTEN ${ }^{1}$, C.B. PHILLIPS ${ }^{2}$, \\ F.L. WÄCKERS ${ }^{3}$ and S.P. WORNER ${ }^{1}$ \\ ${ }^{1}$ National Centre for Advanced Bio-Protection Technologies, \\ PO Box 84, Lincoln University, Canterbury, New Zealand \\ ${ }^{2} A g R e s e a r c h$, Biocontrol and Biosecurity Group, PO Box 60, Lincoln, \\ New Zealand \\ ${ }^{3}$ Netherlands Institute of Ecology (NIOO-KNAW), Centre for Terrestrial \\ Ecology, Boterhoeksestraat 48, 6666 GA Heteren, The Netherlands
}

Corresponding author: vattalad@lincoln.ac.nz.

\begin{abstract}
Lifetime carbohydrate levels were compared in the laboratory between unfed and honey-fed Microctonus hyperodae (Hymenoptera: Braconidae), a parasitoid of the Argentine stem weevil, Listronotus bonariensis (Coleoptera: Curculionidae). High performance liquid chromatography (HPLC) was used to analyse sugars in individual parasitoids and showed that fed and unfed parasitoids can be distinguished by measuring the total sugar levels. Furthermore, the fructose/total sugar ratio (f/T) of honey-fed $M$. hyperodae was always higher than that of the unfed individuals. This method should prove very useful for determining the nutritional status of field-collected parasitoids, and for evaluating the benefits gained by parasitoids through the provision of floral resources in the field.
\end{abstract}

\section{INTRODUCTION}

Carbohydrates are the main energy source for adult parasitoids, which feed on several different sugar sources, such as floral and extrafloral nectar, and aphid honeydew (Jervis et al. 1993). If the energy reserves that parasitoid adults carry over from their larval stage are not supplemented by additional sugar sources, then their activities could be curtailed. Many laboratory experiments have shown that sugar can increase the longevity and fecundity of parasitoids (Wäckers 2001; Gurr et al. 2004; Vattala et al. 2004), and can even change their sex ratios (Berndt \& Wratten 2005). Also, parasitoid host searching activity (Takasu \& Lewis 1995; Landis et al. 2000) and parasitism rates (Leius 1967) can be increased in the field by provision of sugar sources.

Several studies have examined changes in nutrient levels during the lifetimes of parasitoid adults. Olson et al. (2000) used the anthrone test (van Handel 1967) to quantify changes in the levels of fructose, glycogen and total sugars in fed and unfed parasitoids. Wäckers \& Steppuhn (2003) and Steppuhn \& Wäckers (2004) developed a more sensitive method using HPLC to identify and quantify a range of sugars in individual parasitoids. These studies showed that fed parasitoids had higher sugar levels than unfed parasitoids, at least for the initial part of their adult life, and that they lived longer.

The endoparasitoid Microctonus hyperodae Loan (Hymenoptera: Braconidae) investigated in this study is an introduced biological control agent of Listronotus bonariensis (Kuschel) (Coleoptera: Curculionidae) (McNeill et al. 2002). Previous studies have shown that the longevity of M. hyperodae adults can be significantly increased by provision of either glucose or honey solutions (Hodgson et al. 1993; Phillips 1998). Unfed M. hyperodae adults lived 10 days with water in the laboratory (Hodgson et al. 1993; Vattala et al. 2004), which was an unexpectedly long time because many other parasitoids live only 2-3 days without sugar. More recent laboratory experiments have shown that $M$. hyperodae will feed from flowers and that nectar can 
increase its longevity to 21 days (Vattala et al. 2004). A field study of M. hyperodae and L. bonariensis population dynamics showed that adult parasitoids are abundant but hosts are scarce during early summer (Phillips et al. 1998). Analysis indicated that enhancing $M$. hyperodae longevity during this period, perhaps through provision of nectar sources, could improve suppression of L. bonariensis (Phillips et al. 1998).

To exploit this opportunity to improve biological control, it is important to gain a better understanding of how sugar sources influence the energy reserves of M. hyperodae adults. Accordingly, this study addressed the following questions: What is the mean body sugar level in recently eclosed $M$. hyperodae adults and how does this change over time if they do not have access to sugar? What are the effects of sugar feeding on M. hyperodae body sugar levels? Is it possible to develop a biochemical method to discriminate between fed and unfed $M$. hyperodae?

\section{MATERIALS AND METHODS}

Adult L. bonariensis were collected by sweeping grasses at night, either at the Lincoln University Dairy Farm, or from roadside verges near Lincoln. Weevils were maintained in the laboratory at $20^{\circ} \mathrm{C}\left( \pm 2^{\circ} \mathrm{C}\right)$ and $16: 8 \mathrm{~h}$ light:dark photoperiod to allow parasitoids to emerge and develop to the pupal stage. Rearing methods for parasitoids followed Goldson et al. (1993). Cages were checked for cocoons every $24 \mathrm{~h}$ and all cocoons were transferred to Petri dishes that were kept under the conditions noted above. A cotton bud soaked in water was placed in each Petri dish to maintain high humidity. The dishes were checked every $24 \mathrm{~h}$ for newly emerged parasitoids.

Newly emerged parasitoid adults were maintained separately in individual Petri dishes. The two treatments involved providing parasitoid adults with ad libitum access either to $50 \%$ honey solution or water only. These liquids were made available on a piece of cotton wool placed in each Petri dish and were replenished every 2 days. As they emerged, parasitoid adults were randomly assigned to a treatment using a table of random numbers. A sub-sample of parasitoids from the honey treatment was frozen daily at $-80^{\circ} \mathrm{C}$ from age 1 to 9 days, and every second day thereafter, up to the maximum longevity of 19 days. In the water treatment, a sub-sample of parasitoids was frozen at $-80^{\circ} \mathrm{C}$ daily from age 1 to the maximum longevity of 8 days. The number of replicates for each age category ranged from 3 to 10 parasitoids per treatment. In addition, twelve recently emerged parasitoids were not subjected to the experimental treatments, but were frozen at $-80^{\circ} \mathrm{C}$ for subsequent analysis of sugar levels.

Before transferring parasitoids from the freezer to $70 \%$ ethanol for analysis of sugar levels, parasitoid size was estimated by measuring the length of the hind tibia (Phillips \& Baird 2001). HPLC analysis was conducted as described by Steppuhn \& Wäckers (2004) to detect the following sugars in M. hyperodae: sorbitol, manitol, trehalose, glucose, fructose, melibiose, sucrose, melezitose, raffinose, maltose and erlose.

SPSS 12 was used for statistical analysis. The ratio of fructose to total sugars (f/T) was not normally distributed and therefore non-parametric statistics were used. For parasitoids aged from 2 to 8 days, within day comparisons between the two treatments were made using the Mann-Whitney U-test.

\section{RESULTS}

The major fraction of total sugars of newly-emerged parasitoids was glucose (64\%), followed by maltose $(17 \%)$ and fructose $(12 \%)$. In addition, small amounts of sucrose and sorbitol were detected. Trehalose was not detected in newly-emerged parasitoids.

The mean sugar level of newly emerged parasitoids was $17.3 \pm 2.55 \mu \mathrm{g}$ $( \pm$ SE; $n=12)$. The total sugar level declined with age in unfed parasitoids (Fig. 1) and had declined to $15 \%$ of that at emergence by the eighth day. Glucose was the main sugar detected in unfed parasitoids. Ad libitum honey feeding significantly increased the total sugar level of $M$. hyperodae. On day 2 (after honey had been available for $24 \mathrm{~h}$ ) the total sugar level increased to $73.0 \mu \mathrm{g} /$ parasitoid. The sugar level reached its maximum of $154.7 \mu \mathrm{g} /$ parasitoid on day six (Fig. 1). Total sugar levels subsequently declined to $12.3 \mu \mathrm{g} /$ parasitoid on the nineteenth day. 


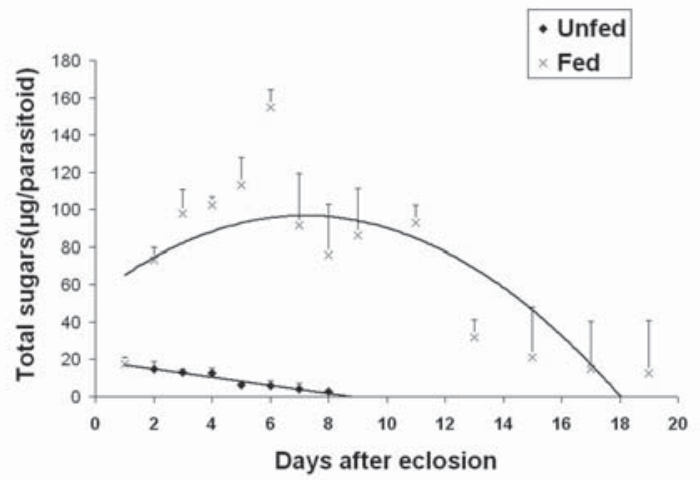

FIGURE 1: Total mean sugar level $(\mu \mathrm{g}$ per parasitoid $+\mathrm{SE})$ of fed $\left(\mathrm{y}=-1.09 \mathrm{x}^{2}+\right.$ $17.53 x+31.31$ and $\left.r^{2}=0.42\right)$ and unfed $\left(y=-2.26 x+19.91\right.$ and $\left.r^{2}=0.40\right)$ M. hyperodae from day 1 to day 19.

Fed parasitoids exhibited higher fructose levels than unfed parasitoids throughout their lifespans $(\mathrm{P}<0.01)$. Fructose levels were approximately equal to those of glucose in fed parasitoids, but were much lower in unfed parasitoids. The common insect haemolymph sugar, trehalose, was not detected in unfed M. hyperodae, but was detected in fed parasitoids after honey had been available for $24 \mathrm{~h}$, and was thereafter continuously present until day 13. Trehalose levels in fed parasitoids remained extremely low compared with other sugars, and the maximum level recorded was $1.3 \mu \mathrm{g} /$ parasitoid on day 9 .

The ratio of fructose/total sugars (f/T) for newly-emerged parasitoids was 0.1157 . The f/T ratio was always lower than 0.1157 for unfed parasitoids and always higher for fed parasitoids (Fig. 2). There was no significant relationship between total body sugar levels and tibia length $\left(\mathrm{P}>0.05\right.$ and $\left.\mathrm{r}^{2}=0.13\right)$.

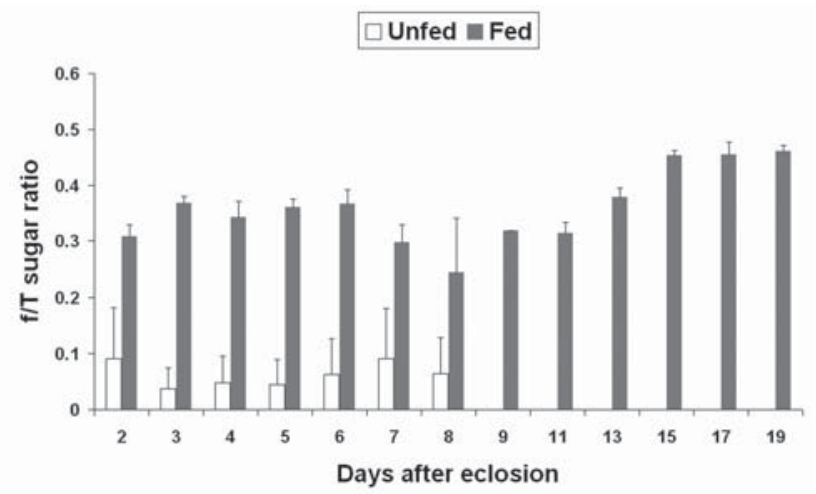

FIGURE 2: Fructose/total sugar (f/T) ratio of recently-emerged, unfed and fed parasitoids. Differences between fed and unfed parasitoids are significant by day 2 ( $24 \mathrm{~h}$ after feeding, $\mathrm{P}<0.01)$. Error bars are one standard error of the mean. 


\section{DISCUSSION}

In previous laboratory experiments, unfed $M$. hyperodae lived 10 days with water only (Hodgson et al. 1993; Vattala et al 2004). This is of interest because other parasitoid species studied in similar experiments lived only 2-3 days (Steppuhn \& Wäckers 2004; Scarratt 2002). HPLC analysis revealed that female $C$. glomerata and $M$. mediator had almost depleted their body sugars by the second day following emergence (Steppuhn \& Wäckers 2004). In contrast, body sugar in unfed M. hyperodae declined to $50 \%$ of its initial level in about 5 days, and to $15 \%$ by the eighth day (Fig. 1). This apparently more gradual decline in total body sugar may facilitate the survival of $M$. hyperodae in the absence of sugar sources. This might be an interesting adaptation because the main habitats of this parasitoid are grasslands, which are often depauperate in nectar sources.

Fructose levels were clearly different between fed and unfed parasitoids. Newlyemerged and unfed parasitoids always had low fructose levels, thus their f/T ratios were also low. In contrast, fructose levels in fed parasitoids increased immediately after feeding, and thereafter remained equal to those of glucose, giving a f/T ratio high throughout their lifespans. This indicates the f/T ratio can provide a clear indication of whether or not a parasitoid has fed, and should prove very useful for evaluating the extent to which flowers are used by parasitoids in the field.

The limited data available on the rate of depletion of parasitoid carbohydrate reserves have all been derived from laboratory experiments (Scarratt 2002; Steppuhn \& Wäckers 2004). In the present study, carbohydrate reserves were measured in parasitoids that were confined in Petri dishes, thus parasitoid flight did not occur, walking was greatly restricted and oviposition in hosts was impossible. In contrast, parasitoid activity should be greatly increased in the field because host searching must occur in a large and complex environment, and the act of ovipositing in hosts may demand significant additional energy. This indicates carbohydrate reserves in unfed parasitoids could become depleted much more quickly in the field than has been observed in laboratory experiments. In contrast, assuming the longevity of parasitoids is not strongly limited by predation and other mortality factors, it is plausible that parasitoids which have access to sugar in the field could replenish their carbohydrate reserves sufficiently frequently to live approximately as long as fed parasitoids in the laboratory. Thus, the beneficial effects of sugar feeding by parasitoids in the field could be even greater than those currently suggested by laboratory experiments. Additional laboratory experiments which more realistically simulate field conditions by using larger cages which contain plants and hosts could be used to make an initial assessment of this possibility.

\section{ACKNOWLEDGEMENTS}

The authors gratefully acknowledge Technology New Zealand for funding the Ph.D programme of HD Vattala. The authors are also grateful to Lester Fletcher (AgResearch, Lincoln), Bruce Garrett (Wrightson Research), and Roel Wagenaar and other staff at the Netherlands Institute of Ecology (NIOO-KNAW), Centre for Terrestrial Ecology, The Netherlands, for their assistance with HPLC analysis.

\section{REFERENCES}

Berndt L, Wratten SD 2005. Effects of alyssum flower on the longevity, fecundity, and sex ratio of the leafroller parasitoid Dolichogenidea tasmanica. Biological Control 32: $65-69$.

Goldson SL, McNeill MR, Proffitt JR, Baker GM, Addison PJ, Barratt BIP, Ferguson CM 1993. Systematic mass rearing and release of Microctonus hyperodae (Hymenoptera: Braconidae Euphorinae) a parasitoid of the Argentine stem weevil Listronotus bonariensis (Coleoptera: Curculionidae) and records of its establishment in New Zealand. Entomophaga 38: 527-536.

Gurr G, Wratten SD, Altieri MA 2004. Ecological Engineering for Pest Management: Advances in Habitat Manipulation for Arthropods. CSIRO publishing, Collingwood Victoria, Australia. 232 p. 
Hodgson DJ, Potter MA, Lovei GL, McNeill MR, Goldson SL 1993. The effect of water, glucose and pollen as dietary components on the longevity of adult Microctonus hyperodae (Hymenoptera: Braconidae, Euphorinae), a parasitoid of Listronotus bonariensis (Coleoptera: Curculionidae). Proceedings of the 6th Australasian Conference on Grassland Invertebrates Ecology. Pp. 384-390.

Jervis MA, Kidd NAC, Fitton MG, Huddleston T, Dawah HA 1993. Flower-visiting by hymenopteran parasitoids. Journal of Natural History 27: 67-105.

Landis DA, Wratten SD, Gurr GM 2000. Habitat management to conserve natural enemies of arthropod pests in agriculture. Annual Review of Entomology 45: 175-201.

Leius K 1967. Influence of wild flowers on parasitism of tent caterpillar and codling moth. The Canadian Entomologist 99: 444-446.

Loan CC, Lloyd DC 1974. Description and field biology of Microctonus hyperodae Loan, n.sp. (Hymenoptera: Braconidae, Euphorinae) a parasite of Hyperodes bonariensis in South America (Coleoptera: Curculionidae). Entomophaga 19: 7-12.

McNeill MR, Goldson SL, Proffitt JR, Phillips CB, Addison PJ 2002. A description of the commercial rearing and distribution of Microctonus hyperodae (Hymenoptera: Braconidae) for biological control of Listronotus bonariensis (Kuschel) (Coleoptera: Curculionidae). Biological Control 24: 165-175.

Olson DM, Fadamiro H, Lundgren LG, Heimpel GE 2000. Effects of sugar feeding on carbohydrate and lipid metabolism in a parasitoid wasp. Physiological Entomology 25: $17-26$

Phillips CB 1998. Influence of liquid food on fecundity and longevity of Microctonus hyperodae Loan. Proceedings of the 51st New Zealand Plant Protection Conference: 23-27.

Phillips CB, Proffitt, JR, Goldson SL 1998. Potential to enhance the efficacy of Microctonus hyperodae Loan. Proceedings of the 51st New Zealand Plant Protection Conference: 16-22.

Phillips CB, Baird DB 2001. Geographic variation in egg load of Microctonus hyperodae Loan (Hymenoptera: Braconidae) and its implications for biological control success. Biocontrol Science and Technology 11: 371-380.

Steppuhn A, Wäckers FL 2004. HPLC sugar analysis reveals the nutritional state and the feeding history of parasitoids. Functional Ecology 18: 812-819.

Scarratt SL 2002. The physiological effects of sugar feeding and their implications for biological control in the parasitic wasp Cotesia rubecula (Marshall) (Hymenoptera: Braconidae). Bachelor of Science (Honors) thesis, University of Adelaide, Adelaide, Australia. $112 \mathrm{p}$.

Takasu K, Lewis WJ 1995. Importance of adult food sources to host searching of the larval parasitoid Micropilitis croceipes. Biological Control 3: 70-74.

van Handel E 1967. Determination of fructose and fructose-yielding carbohydrates with cold anthrone. Analytical Biochemistry 19: 193-194.

Vattala HD, Wratten SD, Phillips CB, Wade MR 2004. The potential of conservation biological control to increase the efficacy of the Argentine stem weevil parasitoid, Microctonus hyperodae Loan. Proceedings of the $8^{\text {th }}$ Australasian Conference on Grassland Invertebrate Ecology. Pp. 165-171.

Wäckers FL 2001. A comparison of nectar and honeydew sugars with respect to their utilization by the hymenopteran parasitoid Cotesia glomerata. Journal of Insect Physiology 47: 1077-1084.

Wäckers FL, Steppuhn A 2003. Characterizing nutritional state and food source use of parasitoids collected in fields with high and low nectar availability. IOBC WPRS Bulletin 26: 203-208. 